
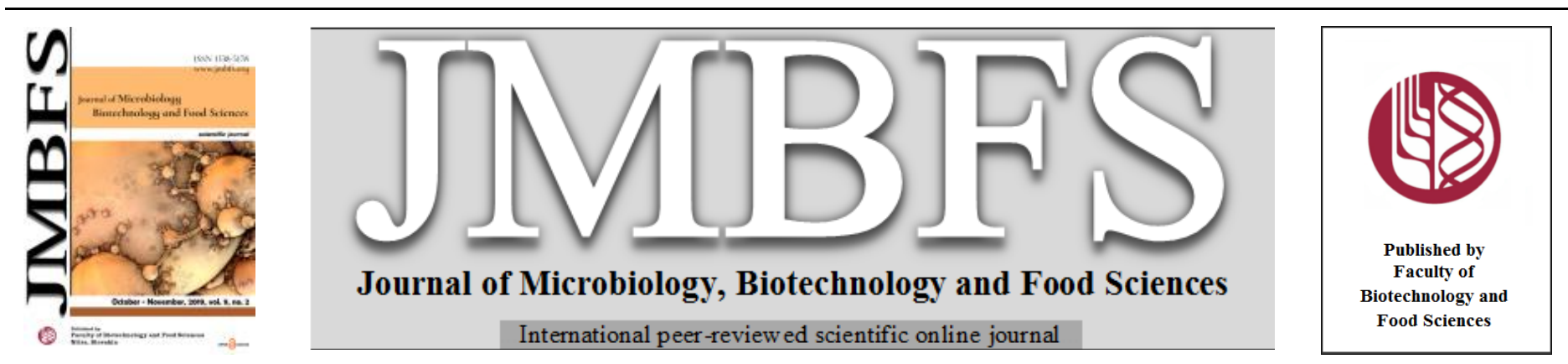

\title{
STATIONARY PHASE SELECTS PREDOMINANTLY CIPROFLOXACIN RESISTANT STRAINS OF SALMONELLA TYPHIMURIUM WITH MUTATION IN GYRA
}

\author{
Ďurišová Kamila*1, Birošová Lucia ${ }^{2}$, Lépesová ${ }^{2}$ Kristína
}

Address(es): Kamila Ďurišová,

${ }^{1}$ Slovak University of Technology, Faculty of Chemical and Food Technology, Institute of Biochemistry and Microbiology, Radlinského 9, 81237 Bratislava, Slovak Republic, 02- 59325512.

${ }^{2}$ Slovak University of Technology, Faculty of Chemical and Food Technology, Institute of Nutrition and Health Protection, , Radlinského 9, 81237 Bratislava, Slovak Republic, 02- 59325478.

*Corresponding author: kamila.durisova@gmail.com

doi: 10.15414/jmbfs.2019.9.2.302-306

\section{ARTICLE INFO}

Received 24. 4. 2019

Revised 18. 6. 2019

Accepted 19. 6. 2019

Published 1. 10. 2019

Regular article OPEN $\bigodot_{\text {ACCESS }}$

\section{ABSTRACT}

This study was focused on determination the mutation frequency leading to ciprofloxacin resistance as well as mechanism of resistance to ciprofloxacin and changes in the ability to form a biofilm at various growth stages of $S$. Typhimurium.

The mutation frequency leading to resistance (resistance index RI) was expressed as the mean number of resistant colonies divided by the mean of the total number of viable cells per culture. The resistance index (RI) was increased linearly over time and it had the highest value in the death phase. The mutations in the Quinolone Resistance Determining sources Regions (QRDR) of gyrA in $S$. Typhimurium strain were identified. All mutations identified in this study were substitutions in the QRDR of the gyrA gene, Serine 83 (Ser 83) and Aspartate 87 (Asp 87). The Ser 83 mutations were found already in exponential phase and their occurrence increased at other growth stages. Point mutations in Asp- 87 were found only in later growth stages. The Ser 83 mutations occurred in all resistant strain obtained from stationary phase, with substitutions by Phenylalanine (Phe). Detection of gyrA mutations was carried out by AS-PCR-RFLP assay. This occurrence correlated with the increased expression of efflux pumps in mutant strains. The highest over-expression of efflux pump was found in resistant strains obtained from $96 \mathrm{~h}$ of cultivation (death phase). Ciprofloxacin resistant mutants formed a biofilm to a greater extent compared to the parental strain. Our data strengthen opinion that stressful environment conditions selects for antibiotic resistant mutants and in case of Salmonella spp. could contribute to improved ability to form biofilm.

Keywords: ciprofloxacin, stationary phase, resistance, Salmonella, biofilm

\section{INTRODUCTION}

Foodborne illness affects approximately $10 \%$ of global population with millions of deaths annually. Salmonella enterica causes foodborne illnesses and outbreaks with significant public health impact (Wang et al., 2019) and salmonellosis is the second most common foodborne disease after campylobacteriosis in the EU (EFSA, 2019a).

Moreover antibiotic resistance in such foodborne pathogens represents a huge global problem. In 2017 most EU countries reported that Salmonella in humans is increasingly resistant to fluoroquinolones (FQ). Multidrug resistance (MDR) is high in Salmonella found in humans and animals, particularly in $S$. Typhimurium (EFSA, 2019b). Pathogenic bacteria are exposed to continually changing, stressful environments such as transitions between different host environments, repeated exposure to antibiotics or attack by host immune systems (Massaey and Buckling, 2002, Singer et al., 2016). These stresses can incorporate also nutrient starvation and extremes in temperature, $\mathrm{pH}$, and/or osmolarity, as well as the presence of reactive oxygen species (e.g. $\mathrm{H}_{2} \mathrm{O}_{2}$ ) and small cationic antimicrobial peptides or proteins (Foster et al., 1995). Thus, in order for the Salmonella spp. to be successful as pathogens, they must be able to sense, respond to, and survive exposures to potentially lethal environmental extremes and hazards encountered in natural microcosm and the arsenal of antimicrobial system initiates within the infected host. A prominent stress encountered by Salmonella spp. is nutrient starvation. $S$. Typhimurium and other bacteria upon starvation undergo a dramatic physiological alteration, the starvation stress response that not only protects the cell against the harmful effects of prolonged starvation but can also provide cross-resistance to other environmental stresses such as oxidative and thermal challenges (Kolodkin-Gal and Engelberg-Kulka, 2009, Naughton et al., 2017). Starved cells are generally more resistant to environmental stress than growing or log-phase cells and because starvation is a common stress encounters by $S$. Typhimurium. The morphologic and physiological changes resulting from C-starvation are called the starvation-stress response (SSR). The SSR functions to provide long-term C-starvation survival and C-starvation-inducible cross- resistance mechanisms to the bacteria. Induction of SSR, particularly by $\mathrm{C}$ starvation, increases bacterial resistance to a number of other environmental stresses including presence of antimicrobials (Kenyon et al., 2007).

FQ due to its broad spectrum activity are used to treat invasive salmonellosis in human and animals (Souza et al., 2010, Wang et al., 2019). FQ resistance increased in past years following the extensive and widespread use. The most commonly recommended FQ is ciprofloxacin which is prescribed with other important FQs such levofloxacin, ofloxacin and norfloxacin for patients with enteric diseases (Kagambèga et al., 2018) The mechanism of action of $\mathrm{FQ}$ is due to inhibition of DNA replication and resistance to FQ is either based on a) mutational alternation in the FQ target enzymes DNA topoisomerases II (DNA gyrase) and DNA topoisomerases IV, or b) Plasmid-Mediated Quinolone Resistance (PMQR) mechanisms or simply, c) decrease uptake of the drug due to the loss of a membrane-bound porin and/or drug extrusion via efflux pump (Zurfluh et al., 2014).

The PMQR qnrA gene encodes a 218 amino acid protein, a member of family of pentapeptides that protect DNA gyrase and topoisomerase IV from FQ activity (Ferrari et al., 2013). PMQR have been reported in Salmonella spp.(SjölundKarlsson et al., 2010).

Mutations in the Quinolone Resistance-Determining Regions (QRDR) of the gyrA and $\operatorname{parC}$ genes alter binding sites for DNA gyrase of these antibiotics and can result in resistance to quinolones. In Salmonella spp., mentioned mutations are related to reduced susceptibility to ciprofloxacin (Cavaco and Aerostrup 2009).

The study is focused on determination the mutation frequency leading to ciprofloxacin resistance in different growth stages of Salmonella enterica subsp. enterica serotype Typhimurium. Consequently, mechanism of resistance in ciprofloxacin resistant strains was studied as well as their ability to form biofilm.

MATERIALS AND METHOD 


\section{Bacterial strains and drugs}

Salmonella enterica, subsp. enterica serovar Typhimurium (CCM 4763, parental strain), Salmonella Typhimurium TA 98 (CCM 3811), Salmonella Typhimurium TA100 (CCM 3812) and Staphylococcus aureus (CCM 885), Pseudomonas aeruginosa (CCM 3955) were received from the Collection of Microorganisms, Masaryk University, Brno (Czech Republic). Salmonella enterica, subsp. enterica serovar Typhimurium mutant strains derived from parental strain were prepared during this study. Ciprofloxacin was purchased from Sigma Aldrich (Germany) and used in assay for susceptibility determination and accumulation of ciprofloxacin.

\section{Determination of mutations frequency leading to antibiotic resistance}

The resistant strains obtained from various stages of growth were derived from parental strain and represent our mutant strains.

The parental strain was grown in antibiotic-free Luria-Bertani (LB) broth for 96 $\mathrm{h}$. The bacterial inoculum $(0.1 \mathrm{ml})$ prepared at various stages of the growth curve (4, 16, 24, 48, 72 and $96 \mathrm{~h}$ ) was added to tubes containing $2 \mathrm{ml}$ top agar. The mixture was vortexed rigorously and poured onto the LB plates containing selective concentration of ciprofloxacin $(0.09 \mu \mathrm{g} / \mathrm{ml})$. Plates were incubated for $72 \mathrm{~h}$ at $37^{\circ} \mathrm{C}$. At the same time, the total number of viable cells was determined on antibiotic-free LB medium. Plates were incubated for $24 \mathrm{~h}$ at $37{ }^{\circ} \mathrm{C}$. The frequency of resistant mutants (resistance index RI) was expressed as the mean number of resistant colonies divided by the mean of the total number of viable cells per culture. Data shown in this study represent the mean of three independent experiments; each experiment was made in five parallels and statistically evaluated by Student's t-test.

\section{Susceptibility determination}

MICs were determined by the standard agar double dilution method on MuellerHinton medium with inoculum of $10^{4} \mathrm{CFU}$ per spot. MICs were determined after $24 \mathrm{~h}$ of incubation at $37{ }^{\circ} \mathrm{C}$, and the results were interpreted according to EUCAST 2019.

\section{Detection of reverse mutations}

The Salmonella mutagenicity assay was performed using classical plate incorporation test (Maron and Ames, 1983) without metabolic activation using Salmonella Typhimurium tester strains TA98 and TA100. A positive response was defined as a reproducible, two fold increase of revertants.

\section{Detection of gyrA mutations by AS-PCR-RFLP}

AS-PCR-RFLP (allele specific - PCR - restriction fragment length polymorphism) assay was provided according to Giraud et al (1999). It was used to detect common mutations related to quinolone resistance at codons 81,83 and 87 of the gyrA gene. PCR amplification was performed with three following primers:

\begin{tabular}{ll}
\hline \multicolumn{1}{c}{ Primer } & \multicolumn{1}{c}{ Sequence } \\
\hline STGYRA1 & 5'-TGTCCGAGATGGCCTGAAGC-3' \\
STGYRAHinfI/87 & 5'- \\
& ATGTAACGCAGCGAGAATGGCTGCGCCATACG \\
& AACGATGGAG-3' \\
AS-81 & 5'-GGTAAATACCATCCCCACG-3' \\
\hline
\end{tabular}

Restriction enzyme HinfI was used for digestion PCR products. Both digested and undigested PCR products were resolved in $3 \%$ (wt/vol) agarose gel in $1 \mathrm{x}$ Tris-borate-EDTA at $120 \mathrm{~V}$ for $2-3 \mathrm{~h}$. A $500 \mathrm{bp}$ DNA ladder was used as a molecular marker.

\section{OmpF preparations}

Expression of outer membrane proteins (OmpF) was determined according to Giraud et al (2000) with slight modifications. Briefly, bacteria were grown overnight, harvest by centrifugation and mechanically disrupted with glass beads. Unbroken cells were removed by centrifugation. The supernatant was incubated with $1 \%$ Triton X-100 and $2 \%$ N-lauroylsarcosine. After ultracentrifugation, proteins were detected by polyacrylamide ge electrophoresis (SDS-PAGE) and protein gels were stained with Coomassie brilliant blue.

\section{Accumulation of ciprofloxacin}

Ciprofloxacin uptake was assayed by the method of Mortimer and Piddock (1991) with some modification. Bacteria were grown to mid-exponential phase at $37^{\circ} \mathrm{C}$ in $\mathrm{LB}$ medium. The growth of bacterial cultures was determined by monitoring the optical density of the culture at $570 \mathrm{~nm}$. Ciprofloxacin was then added to a final concentration of $10 \mu \mathrm{g} / \mathrm{ml}$, and the cells were incubated for 10 min at $37^{\circ} \mathrm{C}$ with shaking. Subsequently, $10 \mathrm{ml}$ of samples were removed at different time interval $(0,5,10,20,30 \mathrm{~min})$, chilled on ice and the cells harvested by centrifugation at $4000 \mathrm{~g}$ for $10 \mathrm{~min}$. The pellet was washed once with $1 \mathrm{ml}$ of saline and resuspended in $1 \mathrm{ml}$ of saline and heated for $10 \mathrm{~min}$ at $100{ }^{\circ} \mathrm{C}$. The samples were then centrifugated at $4000 \mathrm{~g}$ for $10 \mathrm{~min}$. Accumulation of ciprofloxacin in the supernatant was determined in presence and absence of $3,3^{\prime}, 4^{\prime}, 5$ - tetrachlorosalicylanilide (TCS, energy uncoupler, final concentration $30 \mathrm{mmol} / \mathrm{l}$ ) by a microbiological plate assay with $S$. aureus. The inhibition zones produced by $20 \mu \mathrm{l}$ aliquots of supernatant were compared with those produced by $20 \mu$ aliquots of different known concentration of ciprofloxacin using nonlinear regression. The results were expressed as micrograms incorporated per milligram (dry weight) of bacteria. The ciprofloxacin concentration in each intracellular extract was measured by bioassay at least six times. The accepted standard deviation for all the uptake results was always $\leq 5 \%$ with respect to each mean value of several measurements taken at $0 ; 5 ; 10 ; 20$ and $30 \mathrm{~min}$, with or without TCS.

\section{Biofilm formation in vitro}

Quantification of biofilm formation in plastic microtiter plates was based on the described method according to Beenken et al., (2003) in 96-well polystyrene microtiter plates pretreated with horse serum (Oxoid, UK) for $24 \mathrm{~h}$ at $4{ }^{\circ} \mathrm{C}$. Briefly, overnight cultures were diluted 1:200 into tryptic soy broth supplemented with $0.5 \%$ glucose in combination with $3 \%$ sodium chloride. Samples $(200 \square 1)$ were then transferred to the wells of pretreated microtiter plate The plates were incubated without shaking at $37{ }^{\circ} \mathrm{C}$ for $24 \mathrm{~h}$. Subsequently, the wells were washed two times with $200 \square 1$ of phosphate buffer saline to remove nonadherent cells. The remaining attached bacteria were fixed with $200 \square 1$ of $100 \%$ ethanol per well, and after 15 min microplates were emptied and air dried The microplates were stained with $200 \square 1$ per well of Crystal violet used for Gram staining for $5 \mathrm{~min}$. Excess stain was removed, and the wells were washed with phosphate-buffered saline. A quantitative assessment of biofilm formation was obtained by adding $100 \square 1$ of $100 \%$ ethanol and incubating at room temperature for $10 \mathrm{~min}$. A total of $50 \square 1$ of the eluate was then transferred to a sterile polystyrene microtiter plate and the optical density (O.D.) of each well was measured at $630 \mathrm{~nm}$ using an automated SYNERGY|H1 microplate reader (BioTek, CZ).

\section{RESULTS}

\section{Mutation frequency and detection of reverse mutations}

Mutation frequency leading to ciprofloxacin resistance was determined in different stages of growth: at the beginning of the exponential phase $(4 \mathrm{~h})$, at the beginning of stationary phase $(16 \mathrm{~h})$, in early stationary phase $(24 \mathrm{~h})$, in stationary phase $(48 \mathrm{~h})$, in late stationary phase of growth $(72 \mathrm{~h})$ and in death phase $(96 \mathrm{~h})$. Figure 1 shows that mutation frequency leading to ciprofloxacin resistance is increasing with the time of cultivation. After 96 hours we have registered almost 5 fold increase of resistance index. RI of $S$. Typhimurium is linearly dependent with cultivation time.

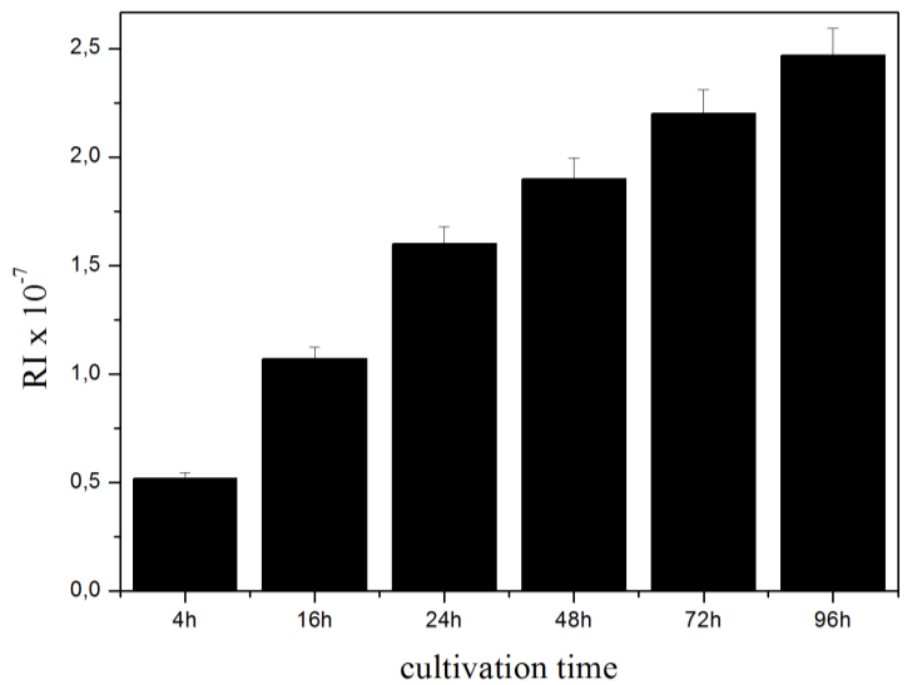

Figure 1 Mutation frequency leading to ciprofloxacin resistance during exponential and stationary phase

To detect spontaneous mutations arising at different growth stages, Ames incorporation mutagenicity test was used on auxotrophic strains of $S$ Typhimurium TA98 (frameshift mutation) and $S$. Typhimurium TA100 (point mutations). As a positive control was applied model mutagen 3-(5-nitro-2furyl) 
acrylic acid (Nfa). According to us, the mutagenicity refers to the production of more than two fold the number of revertants. The mentioned fact was already seen after $24 \mathrm{~h}$ in TA 98. An almost 3-fold increase in revertants was observed. After $48 \mathrm{~h}$ and $72 \mathrm{~h}$, increase in revertants was detected 4.25 times and 9 times, respectively. However, 4 -fold decrease of the number of revertants was observed after 96h due to the bacterial cell death stage. The situation was different in $S$. Typhimurium TA100. No significant changes in the number of revertants were detected after $24 \mathrm{~h}$ (1.5 times) and $48 \mathrm{~h}$ (1.4 times), respectively. As seen in Table 1 , the number of revertants increased 2 - fold after $72 \mathrm{~h}$ and $96 \mathrm{~h}$, respectively. We found out changes in occurrence of reverse mutation between strains, $S$. Typhimurium TA98 and $S$. Typhimurium TA100. The data of Table 2 shows the fact, that the number of revertants was increasing with cultivation time at various stages of growth. From the results of the Ames test is clear, that reverse mutation occurred in mutant strains are point mutations.

Table 1 Development of reverse mutations at various stages of growth without metabolic activation

\begin{tabular}{lcc}
\hline $\begin{array}{l}\text { Cultivation } \\
\text { time (h) }\end{array}$ & TA98 & TA100 \\
\hline 4 & $20 \pm$ SD & M \pm SD \\
\hline 16 & $24 \pm 3.2^{*}$ & $124 \pm 25.4^{*}$ \\
24 & $68 \pm 6.4^{*}$ & $127 \pm 20.23^{*}$ \\
48 & $102 \pm 2.8^{*}$ & $194 \pm 12.5^{*}$ \\
72 & $225 \pm 35.4^{*}$ & $178 \pm 18.61^{*}$ \\
96 & $97 \pm 8^{*}$ & $267 \pm 53.3^{*}$ \\
$\mathrm{Nfa}$ & $442 \pm 34.9^{*}$ & $267 \pm 3.6^{*}$ \\
\hline
\end{tabular}

M -The mean number of revertants plate in $S$. Typhimurium strain TA98 and TA100, SD - Standard deviation, Nfa (3-(5-nitrofuryl)acrylic acid dose $5 \mu \mathrm{g} / \mathrm{ml}-$ positive control, $* \mathrm{p}<0,05$ (t-test)

\section{Susceptibility to ciprofloxacin and mutation in the gyrA gene}

Minimal inhibitory concentration (MIC) of ciprofloxacin (dilution range 0,09$1,56 \mu \mathrm{g} / \mathrm{ml}$ ) were tested in 24 Salmonella enterica, subsp. enterica serovar Typhimurium mutant strains prepared during this study. Distribution of MIC values among tested mutant strains represented full range of ciprofloxacin (Table 2). All tested mutant strains showed MIC of ciprofloxacin ranging from 0,39 $\mu \mathrm{g} / \mathrm{ml}$ to $1,56 \mu \mathrm{g} / \mathrm{ml}$. According to European Committee on Antimicrobial Susceptibility Testing (EUCAST) it means, that all tested mutant strains are considered to be resistant.(EUCAST, 2019).

Table2 Susceptibility to ciprofloxacin of mutant strains $(\mathrm{N}=24)$

\begin{tabular}{|c|c|c|c|c|c|}
\hline \multirow{2}{*}{$\begin{array}{l}\text { Cultivation } \\
\text { time (h) }\end{array}$} & \multirow[b]{2}{*}{0.09} & \multicolumn{4}{|c|}{ MIC $(\mu \mathrm{g} / \mathrm{ml})$} \\
\hline & & 0,18 & 0.39 & 0.78 & 1.56 \\
\hline 4 & 0 & 0 & 15 & 9 & 0 \\
\hline 16 & 0 & 0 & 12 & 12 & 0 \\
\hline 24 & 0 & 0 & 10 & 14 & 0 \\
\hline 48 & 0 & 0 & 0 & 18 & 6 \\
\hline 72 & 0 & 0 & 8 & 15 & 1 \\
\hline 96 & 0 & 0 & 6 & 16 & 2 \\
\hline $\begin{array}{l}\text { susceptibility } \\
\text { of mutant } \\
\text { strains }\end{array}$ & $\begin{array}{c}\mathrm{S} \leq 0.06 \\
\mu \mathrm{g} / \mathrm{ml} \\
\mathrm{N}=0(0 \\
\%)\end{array}$ & & & $\begin{array}{c}\mathrm{R}>0,06 \\
\mu \mathrm{g} / \mathrm{ml} \\
\mathrm{N}=24 \\
(100 \%)\end{array}$ & \\
\hline
\end{tabular}

The table shows number of sensitive (S) or resistant (R) to ciprofloxacin strains The data were evaluated according to European Committee on Antimicrobial Susceptibility Testing (EUCAST, 2019).

All analyzed resistant strains contained mutations in QRDR gyrA gene, at position Ser 83 and Asp 87. Mutations in QRDR region were determined by ASRFLP-PCR analysis of parental strain and mutant strains. AS-RFLP-PCR was used for the screening of point mutations responsible for all amino acid changes encoded by the gyrA gene at codons 83 and 87 . The DNA sequence analysis of parental strain and resistant strains confirmed base substitutions in the codon Ser 83 (Ser $\rightarrow$ Phe) and in the codon Asp 87 (Asp $\rightarrow$ Asn). As may be seen in Figure $1,30 \%$ of resistant strains had mutation in 83 . codon ( $\mathrm{Ser} \rightarrow \mathrm{Phe}$ ) in exponentia phase. The number of resistant strains with this mutation was increased with the passing of cultivation time. At the beginning of stationary phase, $70 \%$ of resistant strains had mutation in 83 codon (Figure 1). In the early to late stationary phase, all resistant strains had a mutation in 83. codon. The Asp $87 \rightarrow$ Asn and Ser $83 \rightarrow$ Phe mutations were present in all resistant strains obtained from 48 and $72 \mathrm{~h}$ of cultivation. Only $25 \%$ of resistant strains purchased from $96 \mathrm{~h}$ of cultivation (death phase) had mutation in gyrA (only in 87. codon).

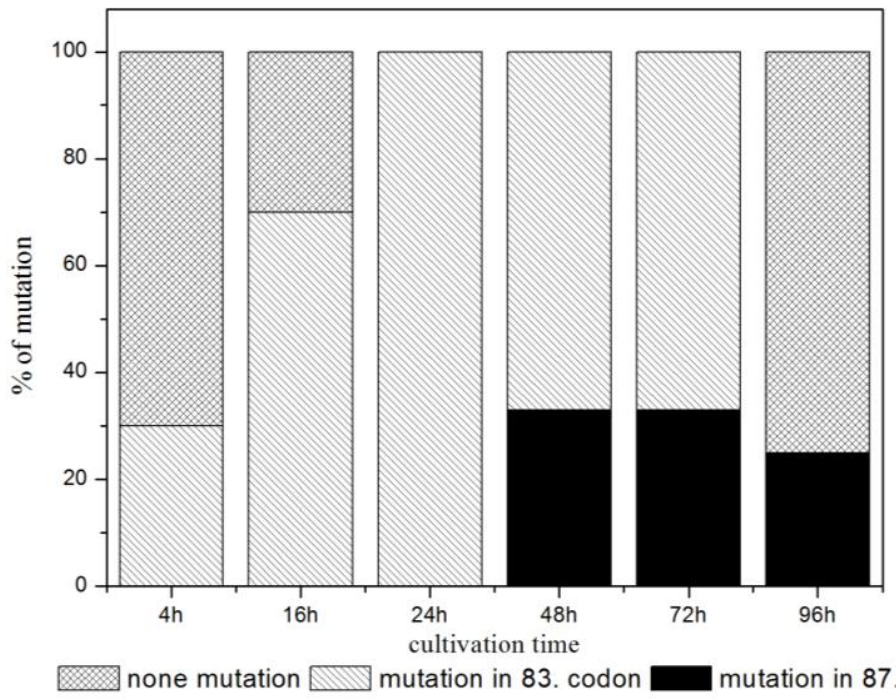

Figure 2 Resistant strains with mutation in $g y r A$ in different growth stages.

\section{Detection of OmpF porins and accumulation of ciprofloxacin}

After analysis of all resistant strains that we compared with the parental strain by SDS-PAGE (Figure 3), we found that there were no significant changes in the amount of OmpF porins compared to the parent strain. All our spontaneous resistant strains had levels of $\mathrm{OmpF}$ proteins equivalent to the parental ciprofloxacin susceptible strain.

Figure 4 shows accumulation of ciprofloxacin by parental strain and mutant strains obtained from stationary phase ( $48 \mathrm{~h}$ of cultivation) in which was detected increased efflux. When energy inhibitor TCS was added after $10 \mathrm{~min}$, accumulation of ciprofloxacin increased rapidly to the same level in both strains Over-expression of efflux pump was detected predominantly in strains from whole stationary phase (more than $60 \%$ of resistant strains) and in all resistant strains obtained from death phase. It is evident, that accumulation of ciprofloxacin increased rapidly. The increase uptake of ciprofloxacin after TCS addition indicated blockage of an energy-dependent ciprofloxacin efflux. This TCS experiment was made as a control measurement for confirmation, that decreased ciprofloxacin uptake is caused by over - expression efflux pumps and not by decreased expression of $\mathrm{OmpF}$.

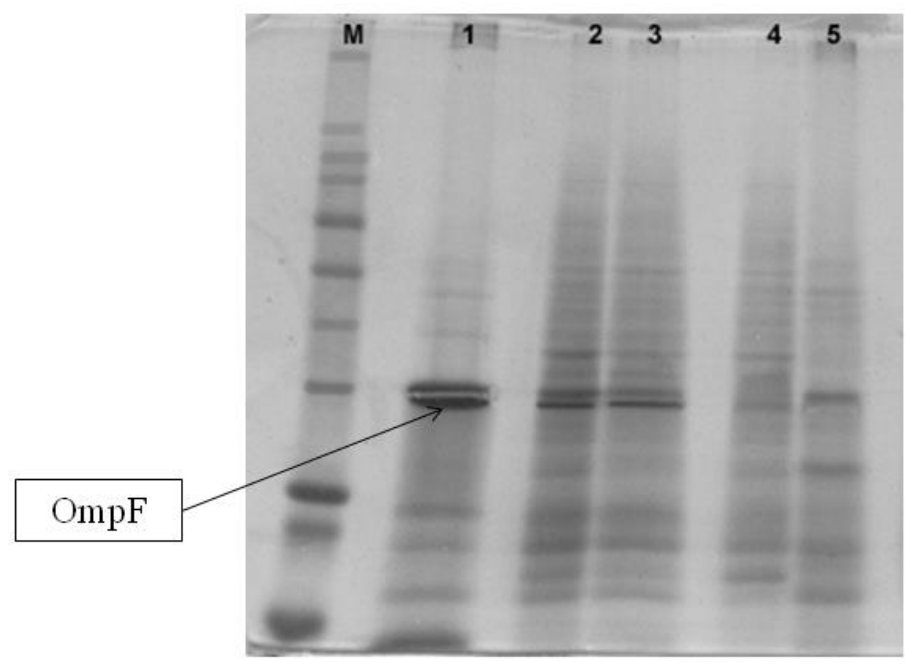

Figure 3 Electrophoretic profiles of OMP prepared from parental strain (lane 1) and some ciprofloxacin resistant strains (lane 2,3), negative control $(4,5$, strains with no expression OmpF). M - Sigma Marker ${ }^{\mathrm{TM}}$ Wide molecular weight range (6.2 - $205 \mathrm{kDa})$. 


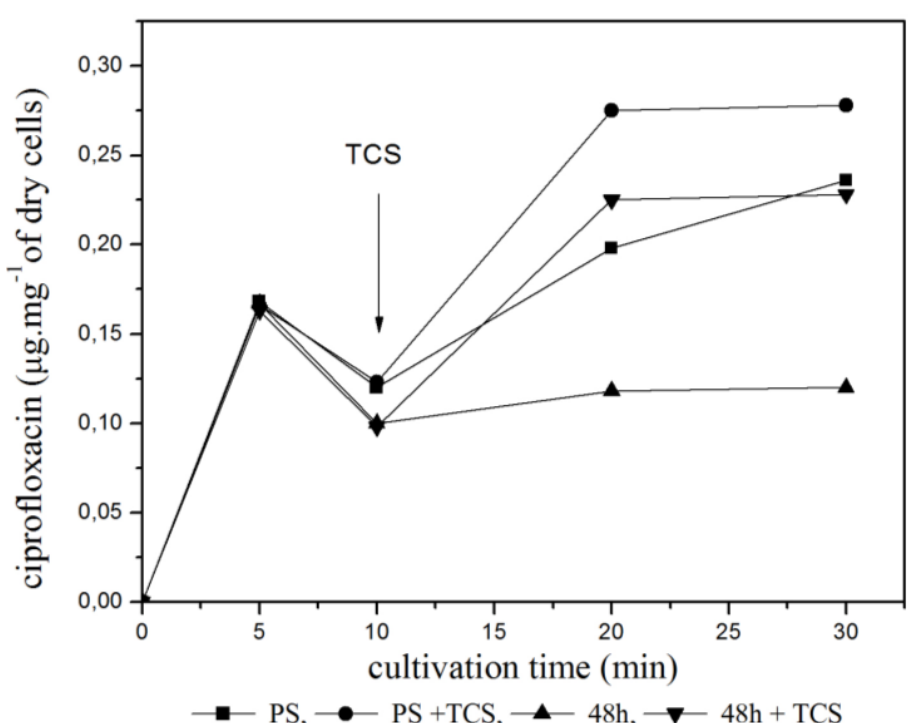

Figure 4 Ciprofloxacin accumulation by parental strain and ciprofloxacin resistant strains, PS-parental strain, 48h-resistant strains obtained from $48 \mathrm{~h}$ of cultivation (stationary phase) were cultivated with and without additions of TCS (final concentration $30 \mathrm{mmol} / \mathrm{L}$ ), which was added at the time indicated by the arrow. All measurements were assayed in parallel.

\section{Biofilm formation}

Biofilm plays an important role in many infectious diseases and cells in biofilm community are resistant to drugs, we were interested how compensatory mutations could affect this unwanted phenomenon. Figure 5 represents development of ability to form biofilm by mutant strains. P. aeruginosa, producer of strong biofilm (OD 0.45) was used as a positive control. As it is evident from Figure 5 parental ciprofloxacin-sensitive strain $S$. Typhimurium has not produced biofilm. On the other hand all ciprofloxacin-resistant strains had the ability to produce biofilm. The strains from late stationary phase $(72 \mathrm{~h})$ appeared as strain which did not produce biofilm.

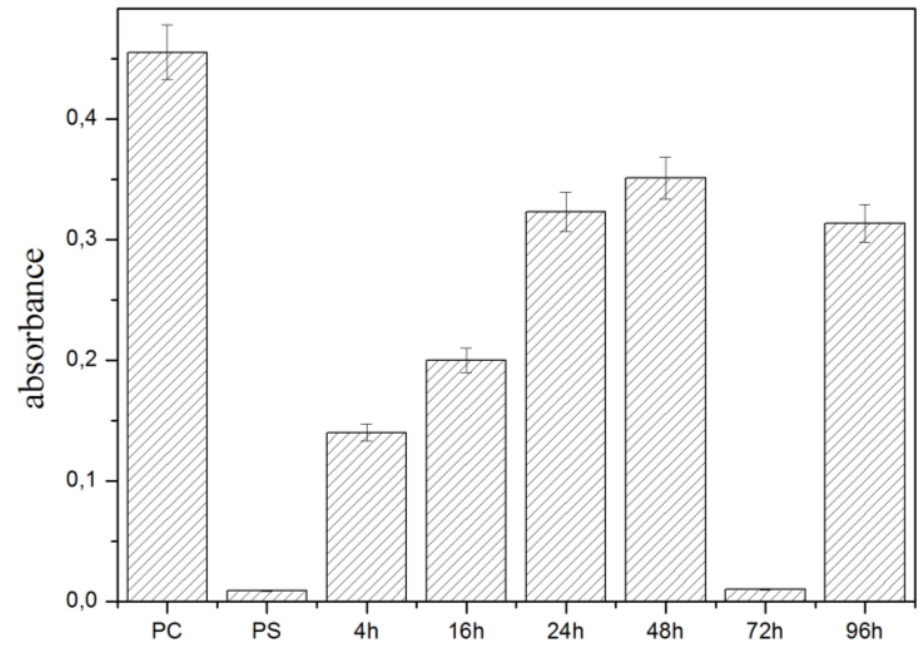

cultivation time

Figure 5 Ability of susceptible parental strain (PS) and resistant strain to form biofilm. P. aeruginosa was used as a positive control (PC).

\section{DISCUSSION}

Antibiotic resistance shows no signs of slowing down and represents huge problem for public health worldwide. Moreover if this phenomenon is associated with foodborne pathogens like Salmonella exposition to people is increasing as well as hospitalization expenses. Antibiotic resistance used to be attributed to the misuse and overuse of antibiotics in human therapy and agriculture (Peng et al., 2018). Mutagenesis leading to antibiotic resistance might be promoted also by other environmental and physiological conditions such starvation or oxidative stress (Birošova and Mikulášová, 2008; Petrosino et al., 2009). In our study we have shown that $S$. Typhimurium in stationary phase in antibiotic-free environment increased frequency of reverse mutations as well as mutations leading to ciprofloxacin resistance. This could be a consequence of nutritional deficiency, toxic products accumulation and generation of oxidative stress. Also some other studies showed that bacteria in stationary phase are more resistant to environmental factors compared to exponential-phase cells (Kolodkin-Gal and Engelberg-Kulka, 2009, Turner et al., 2000 ).This phenomenon correlates with evidence that bacteria in stationary phase markedly exposed to nonlethal selective pressure could develop mutations. These spontaneous mutations occurring in bacteria after prolonged period of incubation on non-lethal selective medium are called adaptive mutations and help bacteria to survive unfitting conditions. (Janion, 2000).

Molecular analysis shown that the all ciprofloxacin resistant mutants contain mutations in QRDR of gyrA. Eighteen resistant strains (74 \%) contained mutation at position Ser 83, six resistant strains $(24,4 \%)$ contained mutation at position Asp 87 and only four resistant strains $(1.6 \%)$ had two mutations.

We found a greater mutation frequency in the codon Ser 83. Giraud et al (2006) reported that mutations in Ser 83 and Asp 87 were not equally distributed among the serovar Salmonella. The occurrence of mutations in the Ser 83 codon is considered to be important for the development of fluoroquinolones resistance (Weigel et al., 2002) a hypothesis that is supported by the results of this study suggest that resistance to ciprofloxacin could indicate occurrence of QRDR mutations.

The differences in susceptibility to ciprofloxacin could by associated to additional mechanism of resistance, such as over -expression efflux pump and modification of porin regulation. The over-expression of efflux pump can be caused by chromosomal mutation or in response to bacterial stress and could play an important role in resistance, especially when FQ are involved Giraud et al (2006). Efflux pump expression is transiently induced through some kind of stimulation. In fact, efflux pump expression is induced by various environmental stressors, such as low $\mathrm{pH}$ and osmotic changes. The mechanism by which efflux pumps are expressed in response to the environment suggests that they might be expressed in the growth environments of bacteria such as at infection sites (Nishino et al., 2009, Birošová and Mikulášová, 2014). We found out that, after addition of TCS, all mutant strains had increased accumulation of ciprofloxacin compared to the parental strain. These results indicated that an active efflux process limits the accumulation of ciprofloxacin by more effective way in the mutant strains than in the parental strains. The role of OmpF in the development of ciprofloxacin resistance was studied comparing mutant strains with their parental strain. SDS - PAGE analysis of outer membranes did not revealed changes in expression of OmpF between mutant strains and parental strain. It means, that resistance to ciprofloxacin in mutant strains is not associated with reduced expression of OmpF, although some studies indicated that stationary phase repress ompF gene resulting in decreased levels of OmpF (Ren et al., 2004, Bougdour, 2004)

Ability to form biofilm belongs to pathogenicity factor and protects bacteria from many undesirable environmental effects. Also antimicrobial resistance can be achieved by biofilm production which can cause increased risk of food safety (Wang et al., 2019).

Yildiz et al. (2004) found out that starvation of Vibrio cholerae cause repression of genes regulating biofilm formation. On the other hand Gerstel and Römling (2001) observed that stationary phase and nutrient starvation improved ability of $S$. Typhimurium to form biofilm. Desai et al (1998) compared the resistance of planktonic and biofilm cells at different stages during exponential growth up to the entry into stationary phase. They found that resistance increased as the planktonic cultures and the biofilm cells approached stationary phase. This feature was confirmed also in our study. The results of evaluation of biofilm formation on microtiter plates by $S$. Typhimurium (parental strain) and derived mutant strains revealed, that all tested mutant strains produced a greater quantity of biofilm than that produced by tested parental strain and it could be induced by $\sigma$-factor entering stationary phase (Kolodkin-Gal and Engelberg-Kulka, 2009) This factor is also participating on activation of many biofilm formation genes. For example. other possible mechanism controlled by $R p o S$ regulon is mismatch repair system. Mutations in genes of DNA repair system were found in biofilmgrowing bacteria and antibiotic resistant strains $P$. aeruginosa. This strain also showed increased fluoroquinolone efflux (Hoiby et al., 2010). Our data strengthen opinion that stressful environment conditions selects for antibiotic resistant mutants and in case of Salmonella could improve ability to form biofilm.

\section{CONCLUSION}

Nowadays antibiotic resistance represents major global problem which is still increasing. Main factor effecting development and dissemination of antibiotic resistant bacterial strains is misuse and overuse of antimicrobial compounds in human and animal therapy, as well as in agriculture. In this study, we have shown that antibiotic resistance can develop also during physiological aging of bacteria, without antibiotic selective pressure. Bacteria in stationary phase are increasing frequency of mutations leading to antibiotic resistance. We have found out that with increasing cultivation time of Salmonella Typhimurium is increasing accumulation of point mutation in gyrA as well as over-expression of efflux pump as two main mechanism of ciprofloxacin resistance. Due to our findings, resistance can also arise in the antibiotic free environment, it is very important to respect the hygiene and Hazard Analysis and Critical Control Points (HACCP) rules both in terms of food safety and overall public health 
Acknowledgments: This work was supported by the Slovak Research and Development Agency under the contract No. APVV-16-0171 and VEGA 1/0096/17.

\section{REFERENCES}

Beenken, K. E., Blevins, J. S., \& Smeltzer, M. S. (2003). Mutation of sarA in Staphylococcus aureus limits biofilm formation. Infection and immunity, 71(7), 4206-4211.

https://doi.org/10.1128/iai.71.7.4206-4211.2003

Birošová, L., \& Mikulášová, M. (2008). The mechanism of ciprofloxacin resistance in dihydrogen peroxide-induced mutants of Salmonella enterica subsp. enterica serovar typhimurium consists mainly in mutations in gyrA gene and less in mutations affecting ciprofloxacin uptake. Folia microbiologica, 53(4), 368. https://doi.org/10.1007/s12223-008-0057-3

Birosova, L., \& Mikulasova, M. (2014). The effect of environmental pollutants and food processing on the development of antibiotic resistance. Biomedical Papers, 158(2), 315-320.

Bougdour, A., Lelong, C., \& Geiselmann, J. (2004). Crl, a low temperatureinduced protein in Escherichia coli that binds directly to the stationary phase $\sigma$ subunit of RNA polymerase. Journal of Biological Chemistry, 279(19), 1954019550.

https://doi.org/10.1074/jbc.M314145200

Desai, M. et al. (1998) Increasing resistance of planktonic and biofilm cultures of Burkholderia cepacia to ciprofloxacin and ceftazidime during exponential growth. J. Antimicrob. Chemother. 42, 153-160

https://doi.org/10.1093/jac/42.2.153

European Committee on Antimicrobial Susceptibility Testing. (2019) Antimicrobial wild type distributions of microorganisms: https://mic.eucast.org/Eucast2/SearchController/search.jsp?action=init

Europan Food Safety Authority (2019a). Salmonella casses in humans: assessing current EU reduction targets: https://www.efsa.europa.eu/en/press/news/190218

Europan Food Safety Authority (2019b). The European Union summary report on antimicrobial resistance in zoonotic and indicator bacteria from humans, animals and food in 2017:

https://www.efsa.europa.eu/en/efsajournal/pub/5598

Ferrari, R., Galiana, A., Cremades, R., Rodríguez, J. C., Magnani, M., Tognim,

M. C. B., ... \& Royo, G. (2013). Plasmid-mediated quinolone resistance (PMQR) and mutations in the topoisomerase genes of Salmonella enterica strains from Brazil. Brazilian Journal of Microbiology, 44(2), 657-662.

http://dx.doi.org/10.1590/S1517-83822013000200046

Foster, John W.; SpectoR, Michael P. How Salmonella survive against the odds. Annual review of microbiology, 1995, 49.1: 145-174.

https://doi.org/10.1146/annurev.mi.49.100195.001045

Gerstel, U., \& Römling, U. (2001). Oxygen tension and nutrient starvation are major signals that regulate agfD promoter activity and expression of the multicellular morphotype in Salmonella typhimurium. Environmental microbiology, 3(10), 638-648.

https://doi.org/10.1046/j.1462-2920.2001.00235.x

Giraud, E., Brisabois, A., Martel, J. L., \& Chaslus-Dancla, E. (1999). Comparative Studies of Mutations in Animal Isolates and Experimental In Vitroand In Vivo-Selected Mutants ofSalmonella spp. Suggest a Counterselection of Highly Fluoroquinolone-Resistant Strains in the Field. Antimicrobial agents and chemotherapy, 43(9), 2131-2137.

https://doi.org/10.1128/AAC.43.9.2131

Giraud, E., Cloeckaert, A., Kerboeuf, D., \& Chaslus-Dancla, E. (2000). Evidence for active efflux as the primary mechanism of resistance to ciprofloxacin in Salmonella enterica serovar Typhimurium. Antimicrobial agents and chemotherapy, 44(5), 1223-1228.

http://doi.org/10.1128/AAC.44.5.1223-1228.2000

Giraud, E., Baucheron, S., \& Cloeckaert, A. (2006). Resistance to fluoroquinolones in Salmonella: emerging mechanisms and resistance prevention strategies. Microbes and Infection, 8(7), 1937-1944.

https://doi.org/10.1016/j.micinf.2005.12.025

Høiby, N., Bjarnsholt, T., Givskov, M., Molin, S., \& Ciofu, O. (2010). Antibiotic resistance of bacterial biofilms. International journal of antimicrobial agents, 35(4), 322-332.

https://doi.org/10.1016/j.ijantimicag.2009.12.011

Janion, C. (2000). A new look at adaptive mutations in bacteria. ACTA BIOCHIMICA POLONICA-ENGLISH EDITION-, 47(2), 451-458.

Kagambèga, A., Lienemann, T., Frye, J. G., Barro, N., \& Haukka, K. (2018) Whole genome sequencing of multidrug-resistant Salmonella enterica serovar Typhimurium isolated from humans and poultry in Burkina Faso. Tropical medicine and health, 46(1), 4

https://doi.org/10.1186/s41182-018-0086-9

Kenyon, W. J., Nicholson, K. L., Rezuchova, B., Homerova, D., Garcia-del Portillo, F., Finlay, B. B., \& Spector, M. P. (2007). бS-Dependent carbonstarvation induction of pbpG (PBP 7) is required for the starvation-stress response in Salmonella enterica serovar Typhimurium. Microbiology, 153(7), $2148-2158$

\section{https://doi.org/10.1099/mic.0.2007/005199-0}

Kolodkin-Gal, I., \& Engelberg-Kulka, H. (2009). The stationary-phase sigma factor $\sigma \mathrm{S}$ is responsible for the resistance of Escherichia coli stationary-phase cells to mazEF-mediated cell death. Journal of bacteriology, 191(9), 3177-3182. https://doi.org/10.1128/JB.00011-09

Naughton, Patrick, Egan, David, Naughton, Violetta and Dooley, James (2016) The Effects of Environmental Stress on the Antibiotic Resistance Phenotype of Salmonella Typhimurium. In: 5th ASM Conference on Salmonella, Potsdam, Germany. ASM Conferences. 1 pp. : http://uir.ulster.ac.uk/36090/

Nishino, K., Nikaido, E., \& Yamaguchi, A. (2009). Regulation and physiological function of multidrug efflux pumps in Escherichia coli and Salmonella. Biochimica et Biophysica Acta (BBA)-Proteins and Proteomics, 1794(5), 834843.

https://doi.org/10.1016/i.bbapap.2009.02.002

Maron, D. M., \& Ames, B. N. (1983). Revised methods for the Salmonella mutagenicity test. Mutation Research/Environmental Mutagenesis and Related Subjects, 113(3-4), 173-215.

https://doi.org/10.1016/0165-1161(83)90010-9

Massey, R. C., \& Buckling, A. (2002). Environmental regulation of mutation rates at specific sites. TRENDS in Microbiology, 10(12), 580-584.

https://doi.org/10.1016/S0966-842X(02)02475-7

Mortimer, P. G. S., \& Piddock, L. J. V. (1991). A comparison of methods used for measuring the accumulation of quinolones by Enterobacteriaceae, Pseudomonas aeruginosa and Staphylococcus aureus. Journal of Antimicrobial Chemotherapy, 28(5), 639-653.

https://doi.org/10.1093/jac/28.5.639

Peng, M., Salaheen, S., Buchanan, R. L., \& Biswas, D. (2018). Alterations of Salmonella enterica Serovar Typhimurium Antibiotic Resistance under Environmental Pressure. Appl. Environ. Microbiol., 84(19), e01173-18.

https://doi.org/10.1128/AEM.01173-18

Singer, A. C., Shaw, H., Rhodes, V., \& Hart, A. (2016). Review of antimicrobial resistance in the environment and its relevance to environmental regulators. Frontiers in microbiology, 7, 1728.

https://doi.org/10.3389/fmicb.2016.01728

Sjölund-Karlsson, M., Howie, R., Rickert, R., Krueger, A., Tran, T. T., Zhao, S., ... \& Fedorka-Cray, P. J. (2010). Plasmid-mediated Quinolone Resistance among Non-TyphiSalmonella enterica Isolates, USA. Emerging infectious diseases, 16(11), 1789

https://doi.org/10.3201/eid1611.100464

Souza, R. B., Ferrari, R. G., Magnani, M., Kottwitz, L., Alcocer, I., Tognim, M. C. B., \& Oliveira, T. C. (2010). Ciprofloxacin susceptibility reduction of Salmonella strains isolated from outbreaks. Brazilian Journal of Microbiology, 41(2), 497-500.

http://dx.doi.org/10.1590/S1517-83822010000200033

Turner, K., Porter, J., Pickup, R., \& Edwards, C. (2000). Changes in viability and macromolecular content of long-term batch cultures of Salmonella typhimurium measured by flow cytometry. Journal of applied microbiology, 89(1), 90-99. https://doi.org/10.1046/j.1365-2672.2000.01086.x

Yildiz, F. H., Liu, X. S., Heydorn, A., \& Schoolnik, G. K. (2004). Molecular analysis of rugosity in a Vibrio cholerae O1 El Tor phase variant. Molecular microbiology, 53(2), 497-515.

https://doi.org/10.1111/j.1365-2958.2004.04154.x

Zurfluh, K., Abgottspon, H., Hächler, H., Nüesch-Inderbinen, M., \& Stephan, R (2014). Quinolone resistance mechanisms among extended-spectrum betalactamase (ESBL) producing Escherichia coli isolated from rivers and lakes in Switzerland. PLoS One, 9(4), e95864

https://doi.org/10.1371/journal.pone.0095864

Wang, X., Biswas, S., Paudyal, N., Pan, H., Li, X., Fang, W., Yue, M. (2019). Antibiotic resistance in Salmonella Typhimurium isolated recovered from the food chain through national antimicrobial resistance monitoring system between 1996 and 2016. Front. Microbiol.07. may, 2019

https://doi.org/10.3389/fmicb.2019.00985

Weigel, L. M., Anderson, G. J., \& Tenover, F. C. (2002). DNA gyrase and topoisomerase IV mutations associated with fluoroquinolone resistance in Proteus mirabilis. Antimicrobial agents and chemotherapy, 46(8), 2582-2587. https://doi.org/10.1128/AAC.46.8.2582-2587.2002 